\title{
Inhibitive Effect by Acid Extract of Ficus Exasperata Leaves on the Sulphuric Acid Corrosion of Mild Steel
}

\author{
N. S. PATEL ${ }^{*}$, S. JAUHARI and G. N MEHTA \\ Chemistry Section Applied Sciences \& Humanities Department, \\ S V National Institute of Technology, Surat-395007, Gujarat, India. \\ niketan.ptl@gmail.com
}

Received 9 April 2009; Accepted 5 June 2009

\begin{abstract}
Extract of Ficus exasperata leaves was investigated as corrosion inhibitor of mild steel in $1 \mathrm{~N} \mathrm{H}_{2} \mathrm{SO}_{4}$ using conventional weight loss, electrochemical polarizations, electrochemical impedance spectroscopy and scanning electron microscopic studies. The weight loss results showed that the extract of Ficus exasperata is excellent corrosion inhibitor. Electrochemical polarizations data revealed the mixed mode of inhibition. The results of electrochemical impedance spectroscopy shows that the change in the impedance parameters, charge transfer resistance and double layer capacitance, with the change in concentration of the extract is due to the adsorption of active molecules leading to the formation of a protective layer on the surface of mild steel. Scanning electron microscopic studies provided the confirmatory evidence of improved surface condition, due to the adsorption, for the corrosion protection.
\end{abstract}

Keywords: Ficus exasperata, Acid corrosion inhibitor, Electrochemical polarization, Electrochemical impedance spectroscopy, Scanning electron microscopic studies, Mild steel

\section{Introduction}

Huge amount of $\mathrm{H}_{2} \mathrm{SO}_{4}$ is used in the chemical industry for removal of the undesired scales and rust. The addition of corrosion inhibitors effectively secures the metal against an acid attack. Many studies in this regard using organic inhibitors have been reported ${ }^{1-5}$. Most of the inhibitors are organic compounds with $\mathrm{N}, \mathrm{S}$ and $\mathrm{O}$ hetero-atoms have higher electron density making them the reaction centres. These compounds are adsorbed on the metallic surface and block the active corrosion sites and most of them are highly toxic to both human beings and environment. Hence use of the natural products as eco-friendly and harmless corrosion inhibitors, has become popular ${ }^{6-14}$.

Ficus exasperata, a moraceae family plant is native to parts of Africa, Arabian Peninsula and India ${ }^{15}$. Alternately arranged, oval and elliptic leaves having a very rough surface, making 
them look like sand paper. The leaves are used for treatment of haemostatic ophthalmia, coughs and haemorrhoid. It is also used for treating various infections and as a sand paper for polishing woods ${ }^{16}$. However, the leaves have never been exploited as the corrosion inhibitor in acid medium. Hence, the present work was aimed at in this direction.

\section{Experimental}

About $5 \mathrm{~g}$ of dried and powdered leaves of Ficus exasperata was refluxed with $1 \mathrm{~N}$ $\mathrm{H}_{2} \mathrm{SO}_{4}$ for about $5 \mathrm{~h}$ and was kept overnight to extract the basic components. The solution was filtered off and the filtrate was diluted with the appropriate quantities of the $1 \mathrm{~N} \mathrm{H}_{2} \mathrm{SO}_{4}$ to obtain the desired concentrations. The aggressive acid solutions used were made of $\mathrm{AR}$ grade of $\mathrm{H}_{2} \mathrm{SO}_{4}$ and diluted with double distilled water. The concentration range of the powdered leaves taken was varied from 25 to $200 \mathrm{ppm}$ in $1 \mathrm{~N} \mathrm{H}_{2} \mathrm{SO}_{4}$.

\section{Specimen preparation}

Cylindrical working electrodes of mild steel (MS) containing $0.09 \% \mathrm{P}, 0.37 \% \mathrm{Si}, 0.01 \% \mathrm{Al}$, $0.05 \% \mathrm{Mn}, 0.19 \% \mathrm{C}, 0.06 \% \mathrm{~S}$ and the remainder Fe, were used for the electrochemical polarisations and impedance measurements. For the weight loss method and scanning electron microscopic (SEM) analysis specimens of $1 \times 1 \mathrm{~cm}$ of same MS were used. The surface preparation of the mechanically polished specimens were carried out using different grades of emery papers, degreased with acetone dried at room temperature and then stored in a desiccator before use.

\section{Weight loss method}

The polished and pre-weighed MS specimens were suspended in $100 \mathrm{~mL}$ test solutions, with and without the extracts of different concentrations, for a fix period of time and were washed, dried and weighed. From the weight loss data, percent inhibition efficiency (IE\%) was calculated.

\section{Electrochemical and impedance measurements}

A three-electrode cell, consisting of a mild steel rod working electrode (WE), a platinum counter electrode (CE), and saturated calomel electrode (SCE) or reference electrode was used for measurements. The electrolyte used was acidic solution maintained at $30{ }^{\circ} \mathrm{C}$. Electrochemical impedance measurements through Nyquist plot and polarization studies through Tafel plot have been carried out using $\mathrm{CH}$ Electrochemical analyzer model $608 \mathrm{C}$ (USA). SEM analysis was carried out using HITACHI model S3400 N scanning electron microscope.

\section{Results and Discussion}

Based on the weight loss measurements, the corrosion rates $(\mathrm{W})$ and the values of inhibition efficiency $\left(\mathrm{IE}_{\mathrm{w}} \%\right)$ for various concentrations of $F$. exasperata extract after $2 \mathrm{~h}$ of immersion at $30{ }^{\circ} \mathrm{C}$ obtained are given in Table 1 .

From the table, it is clear that the value of $\mathrm{IE}_{\mathrm{w}} \%$ increases with the increase in the concentration reaching a maximum value of $93 \%$ at the highest concentration of 200 ppm, suggesting that the number of molecules adsorbed were increased over the MS surface, blocking the active sites of acid attack and thereby protecting the metal from corrosion. 
Table 1. Inhibition Efficiency of MS in $1 \mathrm{~N} \mathrm{H}_{2} \mathrm{SO}_{4}$ in the presence and absence of different concentrations of $F$. exasperata extract.

\begin{tabular}{ccc}
\hline $\begin{array}{c}\text { Concentration of inhibitor, } \\
\mathrm{ppm}\end{array}$ & $\begin{array}{c}\mathrm{W}, \\
\mathrm{mg} / \mathrm{cm}^{2} / \mathrm{h}\end{array}$ & $\begin{array}{c}\text { Inhibition Efficiency, } \\
\mathrm{IE}_{\mathrm{W}} \%\end{array}$ \\
\hline 0 & 16.25 & - \\
25 & 3.42 & 79 \\
50 & 2.40 & 85 \\
100 & 1.77 & 89 \\
150 & 1.43 & 91 \\
200 & 1.12 & 93 \\
\hline
\end{tabular}

The potentiodynamic polarization data are shown in the Tafel plots for MS in $1 \mathrm{~N}$ $\mathrm{H}_{2} \mathrm{SO}_{4}$ with the addition of various concentrations of the additive (Figure 1). The corrosion kinetic parameters such as corrosion potential $\left(\mathrm{E}_{\mathrm{corr}}\right)$, corrosion current density $\left(\mathrm{I}_{\text {corr }}\right)$, anodic and cathodic Tafel slopes $\left(b_{a}\right.$ and $\left.b_{c}\right)$ were derived from these curves and are given in Table 2.

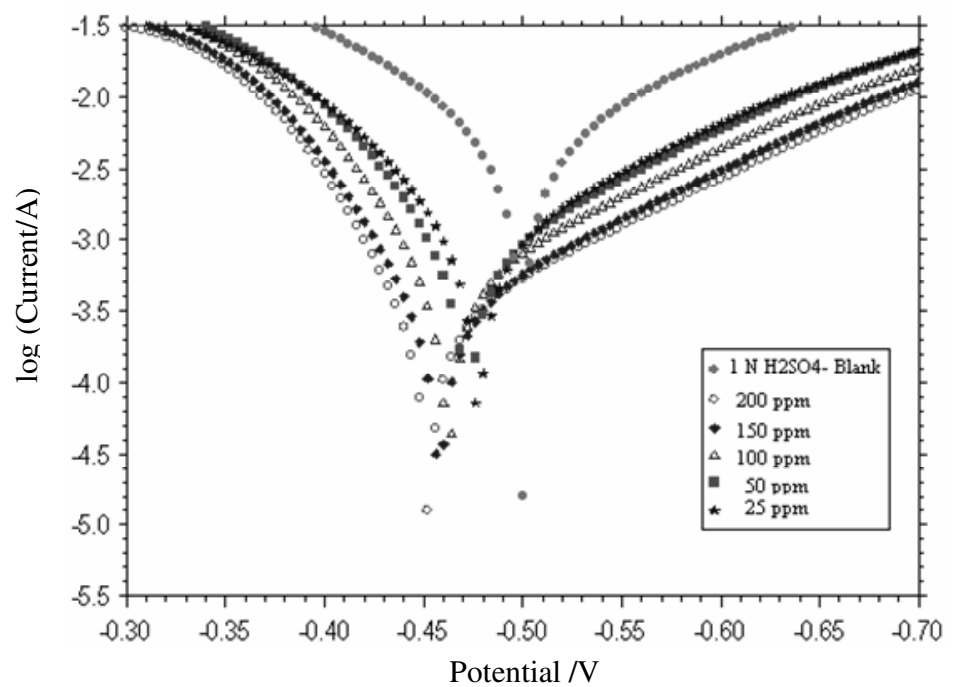

Figure 1. Tafel plots showing effect of $F$. exasperata extracts on corrosion of $\mathrm{MS}$ in $\mathrm{H}_{2} \mathrm{SO}_{4}$. medium.

The values of inhibition efficiency (IE \%) are calculated and tabulated (Table 2). From the Table, it is observed that the $\mathrm{I}_{\text {corr }}$ values gradually decreased with gradual increase in the concentration of additive up to $200 \mathrm{ppm}$ leading to $94 \%$ of IE. Further, there was anodic shift of the $\mathrm{E}_{\text {corr }}$ value of $-0.5 \mathrm{~V}$ (blank) to $-0.45 \mathrm{~V}$ at $200 \mathrm{ppm}$ indicating that the $F$. exasperata extracts acted as an anodic inhibitor ${ }^{17}$ for $\mathrm{MS}$ in $1 \mathrm{~N} \mathrm{H}_{2} \mathrm{SO}_{4}$ which was supported by the gradual and significant decrease of anodic Tafel slope, $b_{a}$ is $143 \mathrm{mV} /$ decade of blank to $79 \mathrm{mV} /$ decade at $200 \mathrm{ppm}$. It could be derived from this decrease that the rate of anodic dissolution was much retarded in comparison to that of cathodic hydrogen evolution. There was decrease of only $22 \mathrm{mV} /$ decade in the corresponding values of cathodic Tafel slopes. This means that the extract must have acted predominantly by blocking anodic sites, and also cathodic sites to some extent, and the extract contained the active molecules which behaved as mixed-type of the acid corrosion inhibitors. 
Table 2. Effect of $F$. exasperata extract on corrosion of MS in $1 \mathrm{~N}_{2} \mathrm{SO}_{4}$ solution studied by Tafel polarisation method

\begin{tabular}{|c|c|c|c|c|c|}
\hline \multirow[t]{2}{*}{$\begin{array}{l}\text { Concentration } \\
\text { of additive, ppm }\end{array}$} & \multirow[t]{2}{*}{$\begin{array}{c}\mathrm{E}_{\text {corr }} \\
\mathrm{V}\end{array}$} & \multicolumn{2}{|c|}{$\begin{array}{c}\text { Tafel Constant, } \\
\text { mV/decade }\end{array}$} & \multirow{2}{*}{$\begin{array}{c}\text { Corrosion Current } \\
\text { Density }\left(\mathrm{I}_{\text {corr. }}\right) \text {, } \\
\mathrm{mA} / \mathrm{cm}^{2}\end{array}$} & \multirow{2}{*}{$\begin{array}{c}\text { Inhibition } \\
\text { Efficiency (IE), } \\
\%\end{array}$} \\
\hline & & $\mathrm{b}_{\mathrm{a}}$ & $\mathrm{b}_{\mathrm{c}}$ & & \\
\hline 0 & -0.4997 & 143 & 160 & 5.91 & - \\
\hline 25 & -0.4768 & 103 & 143 & 1.21 & 80 \\
\hline 50 & -0.4724 & 94 & 138 & 0.97 & 84 \\
\hline 100 & -0.4627 & 90 & 139 & 0.69 & 88 \\
\hline 150 & -0.4582 & 78 & 139 & 0.38 & 94 \\
\hline 200 & -0.4530 & 79 & 138 & 0.35 & 94 \\
\hline
\end{tabular}

The corrosion behaviour of MS in $1 \mathrm{~N} \mathrm{H}_{2} \mathrm{SO}_{4}$, in absence and the presence of various concentrations of $F$. exasperata extract were also investigated by EIS technique. The resultant Nyquist plots are shown in Figure 2. The existence of a single semicircle in each plot shows that there was only single charge transfer process during the anodic dissolution of MS and remained unaffected in the presence of inhibitive molecules of the extract added in the acid.

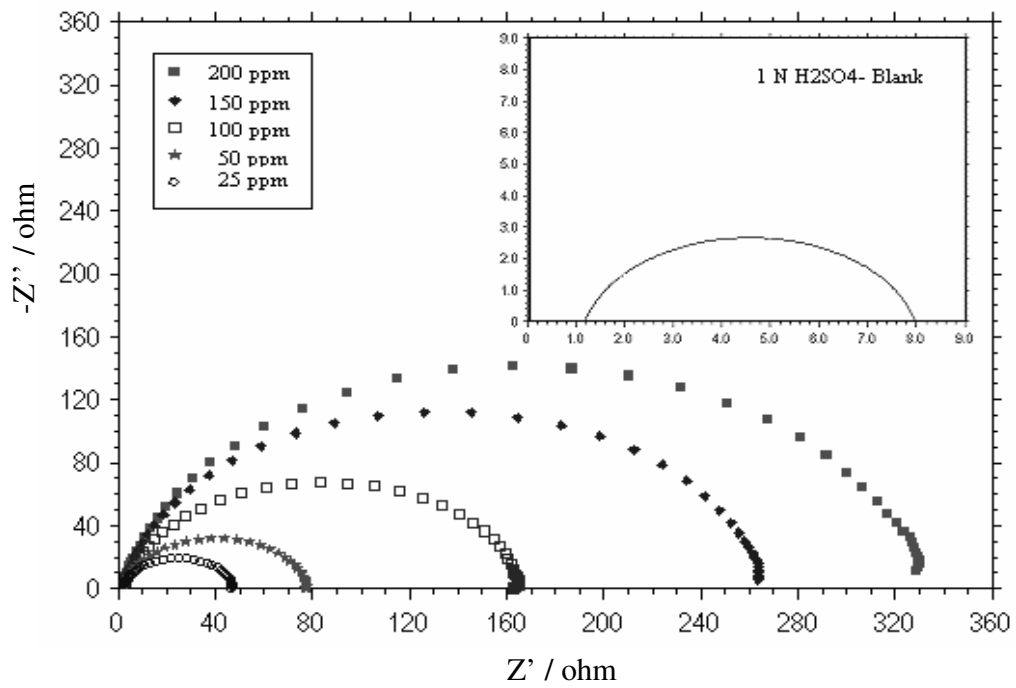

Figure 2. Nyquist plots showing effect of $F$. exasperata extracts on corrosion of MS in $\mathrm{H}_{2} \mathrm{SO}_{4}$ medium.

The charge transfer resistance (Rct) and the interfacial double layer (Cdl) values are derived from these curves and it is found that Rct values increase with increase in the inhibitor concentration while Cdl values decrease which results in maximum IE $(97 \%)$ at high concentration. This indicated that the inhibitive molecules of the extracts have been adsorbed on the MS surface and decreased the roughness of the MS surface.

The SEM photograph in Figure 3(a) has shown that the surface of MS was extremely damaged in the absence of the extract while Figure 3(b) has clearly shown the formation of a film by the active $F$. exasperata constituents on the MS surface which was responsible for the corrosion inhibition. 

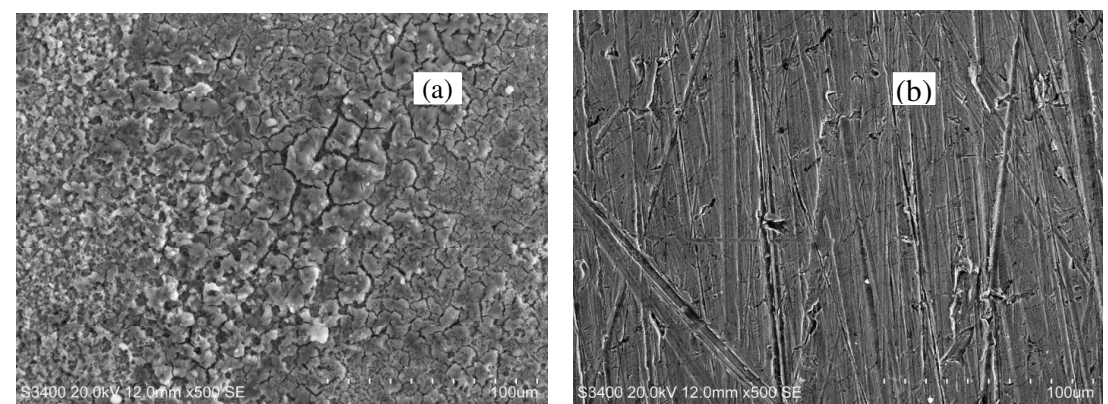

Figure 3. SEM images of MS (a) in $1 \mathrm{~N} \mathrm{H}_{2} \mathrm{SO}_{4}$ media and (b) with $F$. exasperata extract (200 ppm).

The inhibition properties of $F$. exasperata must be due to the presence of nitrogenous compounds ${ }^{18}$ or tannins ${ }^{19}$ in the extract of leaves. However, tannins are complex astringent aromatic acidic glycosides found in various plants and their presence can be ruled out as they are made up of the polyphenols and their acidic and heterocyclic derivatives because such constituents would not have been extracted in the acid.

\section{Conclusions}

- The active molecules present in the extract of $F$. exasperata have effectively inhibited corrosion of mild steel in $1 \mathrm{~N} \mathrm{H}_{2} \mathrm{SO}_{4}$ at $30^{\circ} \mathrm{C}$ by forming a protective barrier layer. The inhibition efficiency of the extract increased gradually with increase in its concentration.

- $\quad$ Polarization measurements have shown that the extract of $F$. exasperata has acted as a mixed- inhibitor, retarding predominantly anodic dissolution of steel in $1 \mathrm{~N} \mathrm{H}_{2} \mathrm{SO}_{4}$.

- The results of the weight loss, electrochemical polarisation and AC impedance spectroscopy were all in very good agreement to support the above conclusions. Photographs by SEM have clearly shown the formation of the protective film on the surface of mild steel.

- $\quad$ The acid extract of $F$. exasperata can be considered as a source of relatively cheap, eco-friendly and effective acid corrosion inhibitors.

\section{Acknowledgements}

The authors thank Dr. P. D. Porey, Director and Dr. M. N. Mehta, Head of Applied Sciences and Humanities Department of S. V. National Institute of Technology, Surat for the scholarship, encouragement and facilities.

\section{References}

1. Achouri M El, Infante M R, F Izquierdo, Kertit S, Gouttoya H M and Nciri B, Corros Sci., 2001, 43, 19-35.

2. Hamner N E and Nathan C C (Ed.). Corrosion Inhibitors, NACE Houston, Texas, USA, 1973,1.

3. Rengamani S, Muralidharan S, Anbu Kulamdainathan M and Venkatakrishna S, $J$ Appl Electrochem., 1994, 24, 355.

4. Bentiss F, Traisnel M and Lagrenee M, Corros Sci., 2000, 42, 127.

5. Arab S T and Noor E A, Corrosion, 1993, 49, 122.

6. Zakvi S J and Mehta G N, Trans SAEST, 1988, 23, 4. 
7. Kar P, Hussein A, Varkey G and Singh G, Trans SAEST, 1997, 28, 2801.

8. Verma S and Mehta G N, Trans SAEST, 1997, 32, 4.

9. Sakthivel P, Nirmala P V, Umamaheswari S, Arul Antony A, Kalignan G P P and Gopalan A, Bull Electrochem., 1999, 15, 83.

10. Verma S and Mehta G N, Bull Electrochem., 1999, 15, 67.

11. Ebenso E and Bok U J I, West Afri J Biol Appl Chem., 1994, 37, 13.

12. Chauhan L R and Gunasekaran G, Electrochim Acta, 2004, 49, 4387.

13. Orubite K O and Oforka N C, Mat Lett., 2004, 58, 1768.

14. Bothi Raja P and Sethuraman M G, Mater Lett., 2008, 62, 113.

15. Keay R W J and Onochie C F A, Nigeria Trees. Vol I \& II. Department of Forestry Research, Ibadan, 1964.

16. Cousins O N and Michael A H, African Study Monographs, 2002, 23(2), 65- 89.

17. Riggs Jr O L and Nathan C C (Ed.), Corrosion Inhibitors, Houston, USA, 1973, 151.

18. Ekpe U J Ebenso E E and Ibok U J, J West African Assoc., 1994, 37, 13- 30.

19. Loto C A, Niger Corr J., 1998, 1(1), 19-20. 


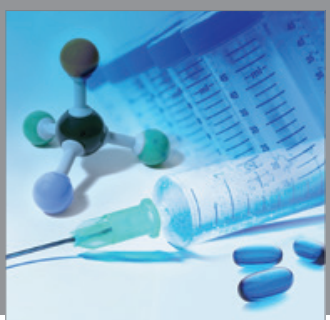

International Journal of

Medicinal Chemistry

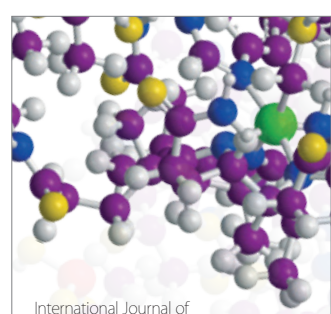

Carbohydrate Chemistry

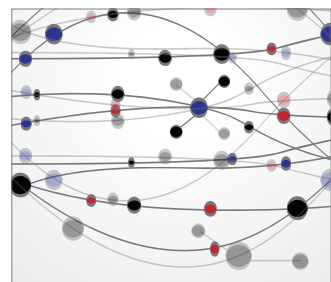

The Scientific World Journal
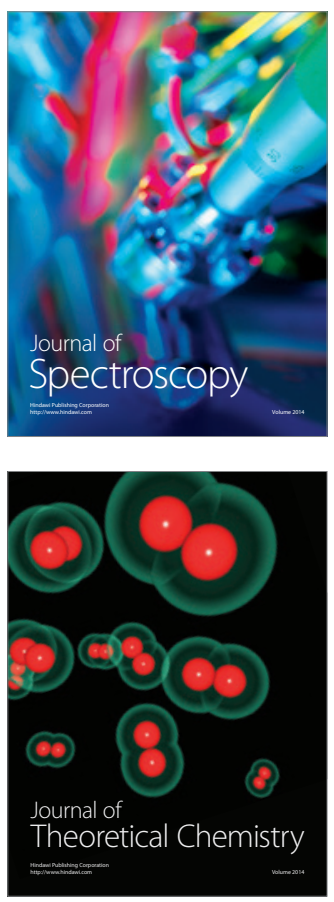
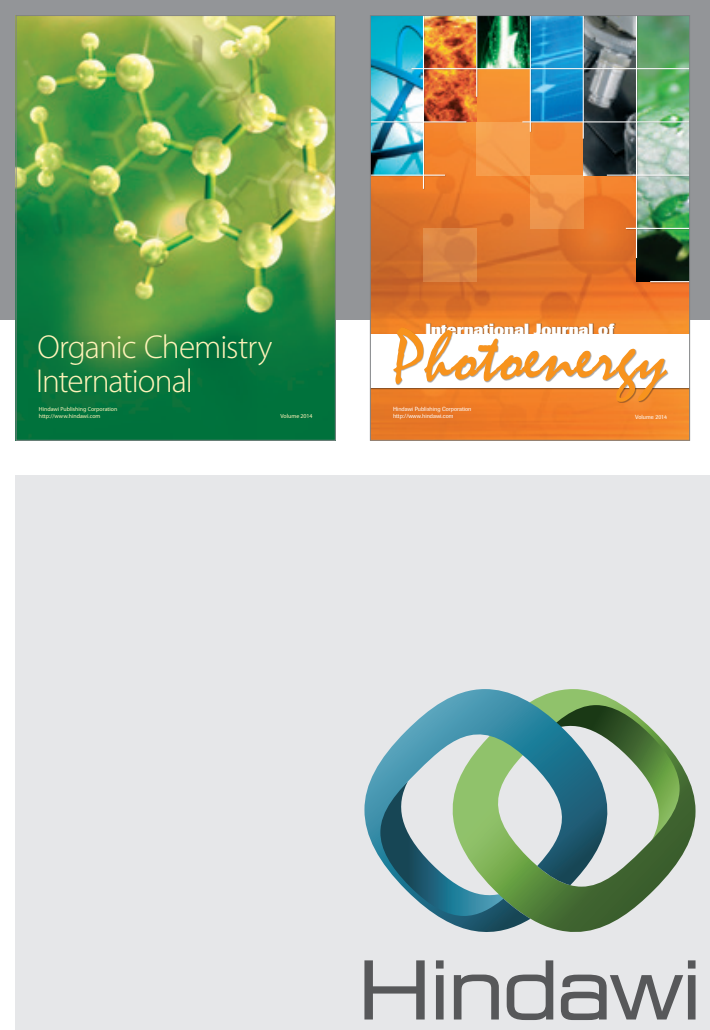

Submit your manuscripts at

http://www.hindawi.com
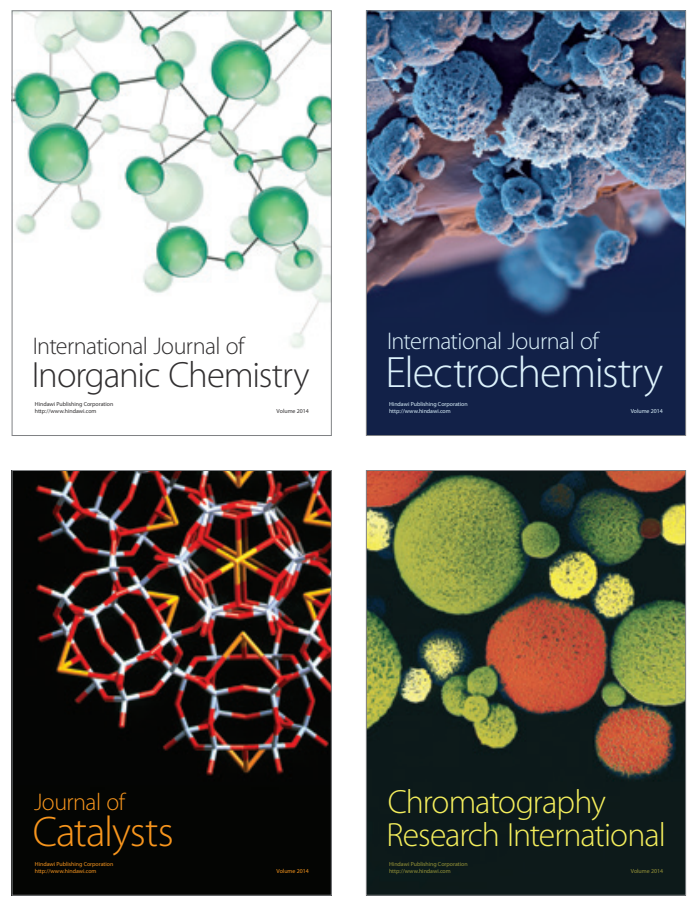
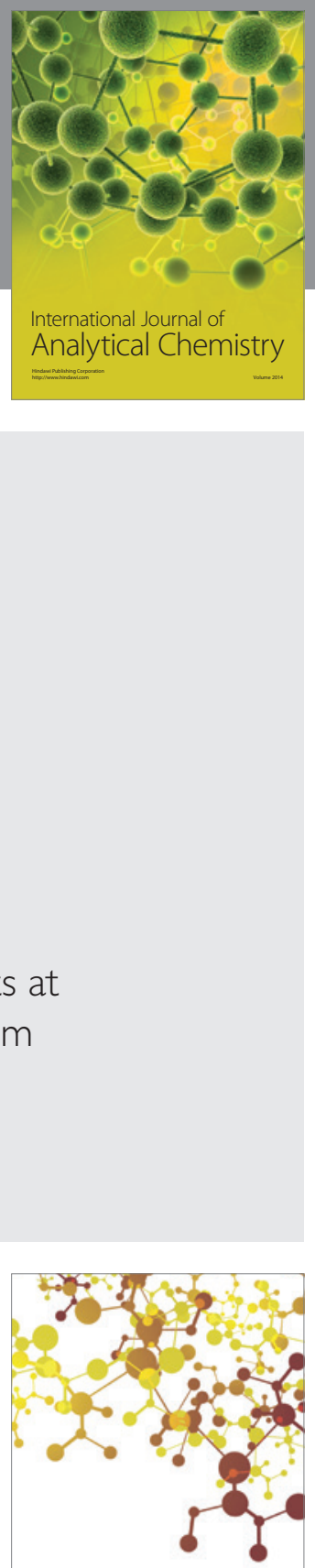

Journal of

Applied Chemistry
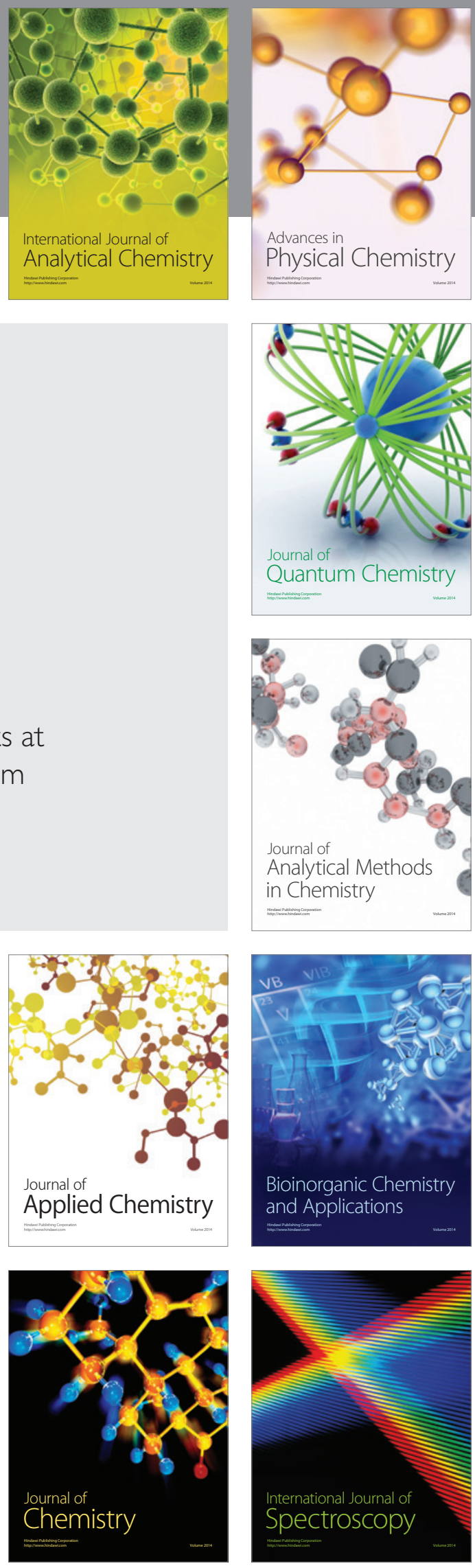